\title{
Integration of biofuel production into district heating - part I: an evaluation of biofuel production costs using four types of biofuel production plants as case studies
}

Danica Djuric Ilic, Erik Dotzauer, Louise Trygg and Göran Broman

\author{
Linköping University Post Print
}

\section{Tweet}

N.B.: When citing this work, cite the original article.

Original Publication:

Danica Djuric Ilic, Erik Dotzauer, Louise Trygg and Göran Broman, Integration of biofuel production into district heating - part I: an evaluation of biofuel production costs using four types of biofuel production plants as case studies, 2014, Journal of Cleaner Production, (69), 176-187.

http://dx.doi.org/10.1016/j.jclepro.2014.01.035

Copyright: Elsevier

http://www.elsevier.com/

Postprint available at: Linköping University Electronic Press

http://urn.kb.se/resolve?urn=urn:nbn:se:liu:diva-106895 


\title{
Integration of biofuel production into district heating - Part I: an
}

\section{evaluation of biofuel production costs using four types of biofuel production plants as case studies}

Danica Djuric Ilic ${ }^{\mathrm{a},}$, Erik Dotzauer ${ }^{\mathrm{b}}$, Louise Trygg ${ }^{\mathrm{a}}$, Göran Broman ${ }^{\mathrm{c}}$

a Division of Energy Systems, Department of Management and Engineering, Linköping University, SE-58183 Linköping, Sweden

${ }^{b}$ School of Sustainable Development of Society and Technology, Mälardalen University, SE-72123 Västerås, Sweden

${ }^{c}$ Department of Strategic Sustainable Development, School of Engineering, Blekinge Institute of Technology, Karlskrona, Sweden

\begin{abstract}
This paper evaluates the effects on profitability of biofuel production if biofuel producers would sell the waste heat from the production to a local district heating system. All analyses have been performed considering four different technology cases for biofuel production. Two technology cases include ethanol production which is followed by by-production of raw biogas. This biogas can be upgraded and sold as biofuel (the first technology case) or directly used for combined heat and power production (the second technology case). The third and the fourth technology cases are Fischer-Tropsch diesel and dimethyl ether production plants based on biomass gasification. Two different district heating price levels and two different future energy
\end{abstract}

\footnotetext{
* Corresponding author. Tel. +46-13-281114; fax: +46-13-281788

E-mail adress: danica.djuric.ilic@liu.se (D. Djuric Ilic)
} 
market scenarios were considered. The sensitivity analyses of the discount rate were performed as well.

In the case of energy market conditions, the profitability depends above all on the price ratio between biomass (used as the feedstock for biofuel production) and crude oil (used as the feedstock for fossil diesel and gasoline production). The reason for this is that the gate biofuel prices (the prices on which the biofuel would be sold) were calculated assuming that the final prices at the filling stations are the same as the prices of the replaced fossil fuel. The price ratios between biomass and district heating, and between biomass and electricity, also have an influence on the profitability, since higher district heating and electricity prices lead to higher revenues from the heat/electricity by-produced.

Due to high biofuel (ethanol + biogas) efficiency, the ethanol production plant which produces upgraded biogas has the lowest biofuel production costs. Those costs would be lower than the biofuel gate prices even if the support for transportation fuel produced from renewable energy sources were not included. If the raw biogas that is by-produced would instead be used directly for combined heat and power production, the revenues from the electricity and heat would increase, but at the same time the biofuel efficiency would be lower, which would lead to higher production costs. On the other hand, due to the fact that it has the highest heat efficiency compared to the other technologies, the ethanol production in this plant shows a high sensitivity to the district heating price level, and the economic benefit from introducing such a plant into a district heating system is most obvious. Assuming a low discount rate $(6 \%)$, the introduction of such a plant into a district heating system would lead to between $28 \%$ and $52 \%$ (depending on the district heating price level and energy market scenario) lower biofuel production costs. Due to the lower revenues from the heat and electricity co-produced, and higher capital investments compared to the ethanol production 
plants, Fischer-Tropsch diesel and dimethyl ether productions are shown to be profitable only if high support for transportation fuel produced from renewable energy sources is included.

The results also show that an increase of the discount rate from $6 \%$ to $10 \%$ does not have a significant influence on the biofuel production costs. Depending on the biofuel production plant, and on the energy market and district heating conditions, when the discount rate increases from $6 \%$ to $10 \%$, the biofuel production costs increase within a range from $2.2 \%$ to $6.8 \%$.

\section{Abbreviations}

BHO, biomass-fuelled heat-only; BCHP, biomass-fuelled combined heat and power; CCP, coal condensing power; $\mathrm{CHP}$, combined heat and power; $\mathrm{CO}_{2}$, carbon dioxide; $\mathrm{DH}$, district heating; DHS, district heating systems; DME, dimethyl ether; EM, energy market; EMS, energy market scenario; ENPAC, Energy Price and Carbon Balance tool; FTD, Fischer-Tropsch diesel; IEA, International Energy Agency; NGCC, natural gas combined cycle; RES-E, electricity produced from renewable energy sources; RES-T, transportation fuel produced from renewable energy sources; SNG, synthetic natural gas; SSF, simultaneous saccharification and fermentation; TS, transport sector; WEO-np, "New Policies Scenario"; WEO-450, “450 scenario”.

\section{Keywords}

Biofuel production; Polygeneration; Energy cooperation; District heating

\section{Introduction}

In 2007, the European Council established an integrated energy and climate change policy known as the 20-20-20 targets (European Commission, 2008). The policy aims to reach $20 \%$ of the total energy use from renewable sources, to reduce greenhouse gas emissions by $20 \%$ 
and to reduce primary energy use by $20 \%$. These targets should be achieved by 2020 . The reference year for those targets is 2005. An additional target is to increase the share of renewable energy in the transport sector (TS) up to $10 \%$. In addition to this, the European Commission has also set a long-term goal to decrease the number of fossil-fuelled cars in the EU by $50 \%$ by 2030 (European Commission, 2011). Sweden's goal for renewable energy in TS for the year 2030 is to achieve complete fossil independence (SEA, 2010).

The transition to renewable energy in the TS is moving more slowly than in the other energy systems (IEA, 2011). A major concern of biofuel production is its economic feasibility. In a number of previous studies different kinds of strategies have been proposed in order to decrease biofuel production costs; e.g. developing industrial symbioses (Gonela and Zhang, 2013) or integrating with an existing combine heat and power (CHP) plant (Starfelt et al., 2010; Starfelt et al., 2009). Generally, a co-production of other products is shown to play a decisive role when the economic performance of biofuel production and efficient utilization of biomass are evaluated. Depending on the different combinations of co-products, overall energy efficiency and biofuel production costs may vary within a wide range (Barta et al., 2010b; Sassner and Zacchi, 2008). Furthermore, a number of studies have been published that evaluate the profitability of investing in biofuel production with a focus on other factors; e.g. with a focus on the whole process configuration (Piccolo and Bezzo, 2009; Porzio et al., 2012; Agostingo and Ortega, 2013) or only on one of the major process steps (Barta et al., 2010a), with the focus on production scale (Sotoft et al., 2010), type of the feedstock (Sassner et al., 2008), and operating hours (Leduc et al., 2009).

Parameters that also have large influences on the biofuel production costs are external factors such as: biomass availability and biomass transportation costs, the possibility to sell the residual heat to a local district heating $(\mathrm{DH})$ system and the possibility to sell the biofuel locally (which decreases the biofuel transportation costs). These parameters should be considered 
when the capacity and the geographical positions of the biofuel production plants are determined. Leduc et al. (2008; Leduc et al., 2010; Leduc et al., 2009) assessed advantageous locations for biomass based methanol production plants in the country of Austria, in Norrbotten in Sweden and in Baden-Württemberg in Germany. In the case studies of Austria (Leduc et al., 2008) and of Norrbotten (Leduc et al., 2010) the results showed that if a methanol production plant is located near a DH system (DHS), by selling the co-produced residual heat the methanol production costs may decrease by $12 \%$ and $10 \%$, respectively. After conducting a transportation model, which minimises the methanol production costs with respect to the biomass transportation costs and the methanol transportation costs, Leduc et al. (2009) concluded that the location of a methanol plant in Baden-Württemberg, Germany may influence those transportation costs by $60 \%$. They also found that a typical optimal capacity of a methanol production plant, with an average transportation distance of biomass of $50 \mathrm{~km}$, is large enough to supply more than 100 gas stations in the region. Large influences of those external factors on the biofuel production costs have been shown in some other studies also. Skarlis et al. (2012) investigated the profitability of investing in a small-scale biodiesel production plant in Crete, Greece, and they found that the investment in such a plant is profitable only if the oil feedstock is available at an acceptable price and if the local biodiesel sale is ensured. Wetterlund et al. (2012; Wetterlund, 2010) assessed proper locations for ethanol, methanol and Fischer-Tropsch diesel (FTD) production plants in the EU. The locations are assessed with a focus on investigating how different parameters (such as energy policy, energy prices, capital costs, biomass availability and heat delivery opportunities) affect: the biofuel production costs, the optimal plant location, the optimal plant capacity and the possible carbon dioxide $\left(\mathrm{CO}_{2}\right)$ emissions reduction. A general conclusion in those studies is that both the $\mathrm{CO}_{2}$ reduction potential and the biofuel production costs are strongly connected to the coproduction and utilization of electricity and heat. When the heat is co-produced, the DH price, 
which is usually determined by local DHS conditions, may have a significant influence on biofuel production costs.

There are also many studies that analyse how the introduction of biofuel production would affect $\mathrm{DH}$ production costs and global $\mathrm{CO}_{2}$ emissions if the $\mathrm{DH}$ producers would invest in biofuel production instead of in CHP production (Djuric Ilic et al., 2012; Fahlén and Ahlgren, 2009; Difs et al., 2010; Wetterlund and Söderström, 2010). In those studies, when the DH production costs are analysed the biofuel produced is considered a by-product so the revenues from biofuel sales are included in the calculations as negative costs. The mentioned studies are described in more detail in the second part of this study (Djuric Ilic et al., 2014).

\subsection{Objective}

In order to increase the share of biofuel used in the TSs in a cost-effective way, the introduction of biofuel production into DHSs can be of great interest. The investment in the biofuel production plants can be made by interdependent companies looking for opportunities to sell the residual heat from the process to a local DHS, or by DH companies interested in increasing the economic efficiency of the DH production by developing new business strategies. This paper is the first part of a two-part study which evaluates the possible economic effects of introducing biofuel production into DHSs from these two stand points. In this first part, it is assumed that the biofuel production plants would be built by interdependent companies.

In many of the previous studies the analyses of the biofuel production costs were performed based on the comparison of different process options, plant's capacities, types of feedstock and different external factors, such as biomass availability and the possibility to sell biofuel and residual heat locally. In some of those studies sensitivity analyses of the feedstock price and by-products' prices have been performed. However, the influences of the energy market (EM) 
conditions and the local DHS conditions on the profitability of the biofuel production have not been analysed in detail.

This paper aims to evaluate the profitability of biofuel production considering different DHS conditions and two different EM scenarios (EMSs) for the future. The period analysed is between 2030 and 2040. The profitability is discussed by comparing the biofuel production costs with the gate biofuel selling prices, which are calculated assuming that the biofuel would be sold to local gas stations. When the biofuel production costs are analysed, the capital (investment) costs and the annual costs (including the revenues from the heat and electricity by-produced) are considered. The analyses are performed for four technology cases which include production of ethanol, biogas, FTD and dimethyl ether (DME). The main focus is on assessing how different DH prices and different annual operating periods of the plant (which usually depends on the DH demand variations) affect the profitability of the biofuel production.

The secondary aim of the paper is to provide a detailed description of the EMSs and a description of the technology cases, which are also used later in the second part of the study. In this second part of the study (Djuric Ilic et al., 2014), an evaluation of the DH production costs if DH producers were to invest in biofuel production (by building biofuel production plants) instead of in CHP production, is conducted. Stockholm's DHS is taken as a case study. In this analysis the revenues from the biofuel and electricity co-produced in the DHS are included as negative costs.

\section{Biofuel production through polygeneration}

The biofuel available on the market today is mostly produced from the edible parts of food plants (first generation biofuels), such as ethanol from sugar or starch crops and biodiesel from vegetable oil. In a number of previous studies, the benefits of the first generation biofuel use have been questioned, mostly due to the trade-offs associated with land use changes (Nguyen 
et al., 2010) and significant consumption of natural resources such as water (Renouf et al., 2013; Pereira and Ortega, 2010; Ponton, J., 2009). The actual contributions to a reduction of fossil fuel use and to greenhouse gas emissions reduction have also been debated (Pereira and Ortega, 2010). On the other hand, lignocellulosic biomass (wood) has been discussed as a promising feedstock for producing biofuels (Ponton, J., 2009), mostly due to its global availability and possibility to reduce competition between biofuel and food production. Furthermore, production from lignocellulosic biomass offers an opportunity for competitive large-scale biofuel supply in countries with high annual forest growth, such as Sweden. These biofuels produced from lignocellulosic biomass are known as second generation biofuels. From this point forward, the term biomass is used to denote lignocellulosic biomass.

Since biomass can be used in a variety of applications including heat, electricity and biofuel production, it is promoted as a key element in the European energy and climate policy. However, biomass is a limited resource so it is of great importance to increase the efficiency of its use. Because of its potential to use biomass efficiently, polygeneration, (i.e., the production of different energy carriers during the same process) is especially interesting.

\subsection{Technology cases included in the study}

Since most of the technologies of biofuel polygeneration production are still at the development stage, a low availability of detailed data has limited the selection of technology cases. The choice of technologies was made by researching the available data from scientific publications. Since the study suggests the introducing of biofuel production into DHSs, only the technologies with by-production of heat were considered. The only feedstock considered is biomass. Finally, four different technology cases were chosen to be included in the study.

Two of the chosen technologies are DME and FTD productions based on biomass gasification. Figure 1 (left hand side of the figure) shows a simplified configuration scheme of such a biofuel 
production process. This type of production generally consists of several steps: pretreatment, (by chipping or drying), thermo-chemical gasification into synthetic natural gas (SNG), purification and upgrading of SNG, and biofuel synthesis (Balat et al., 2009; Wang et al., 2008a; Wang et al., 2008b). The process is exothermic, which opens up a possibility for using the excess heat for DH or combined heat and power (CHP) production.

Despite the fact that production of fuel from gasified coal is well developed and commercial, commercialization of biofuel production through biomass gasification seems to be still far off. A number of development projects on this technology are currently running. In Güssing, Austria, testing and development of SNG synthesis and on FTD synthesis have been performed over the last few years (Hofbauer et al., 2003; Pröll et al., 2007) and the German company Choren has also demonstrated FTD synthesis in a pilot plant with a biomass input capacity of 1 MW (Hellsmark, 2010; Wetterlund, 2012). At Chalmers University of Technology, Gothenburg, Sweden, a gasifier with a flexible capacity of 2-6 MW thermal input, for purposes of high quality SNG production, has been operating since 2007 (Thunman and Seemann, 2009). Construction of a new biomass gasifier plant for commercial SNG production, with an industrial scale of $20 \mathrm{MW}$ SNG output, has also been started in Gothenburg, Sweden (Gunnarsson, 2011). There are also a number of other projects with those technologies, e.g. at the Energy Research Centre of the Netherlands, at the Forschungszentrum Karlsruhe in Germany and at the Energy Technology Centre in Piteå, Sweden (van der Meijden et al., 2010; Hellsmark, 2010; Wetterlund, 2012). An important assumption in this study is that the technology of biofuel production through biomass gasification would be commercial by the year 2030 .

Due to its lower capital intensity compared to ethanol production based on separate enzymatic hydrolysis and fermentation, the ethanol production through polygeneration based on simultaneous saccharification and fermentation (SSF) is more likely to become commercially 
viable (Söderström et al., 2005; Wingren et al., 2003). Thus, two of the technology cases considered in the present study includes ethanol production based on SSF: the ethanol production plant in which the raw biogas co-produced is upgraded and sold as fuel for vehicles (from this point forward denoted as Ethanol 1 plant) and the ethanol production plant in which the raw biogas is used directly for CHP production (from this point forward denoted as Ethanol 2 plant). A simplified scheme of the ethanol production process based on SSF is presented in the right hand side of Figure 1. The first stage of the processes is pretreatment, during which the biomass is transformed into slurry. The slurry is then flash-cooled, $\mathrm{pH}$ neutralised and diluted. SSF is performed with the yeast cultivated in the slurry and after this the ethanol is separated by distillation and dehydrated (Barta et al., 2010a; Sassner et al., 2008). Excess solid residue from the process are treated by anaerobic digestion to produce biogas, which can be used directly as a fuel for CHP production or upgraded and sold as fuel for vehicles. Residue from the anaerobic digestion are utilised for production of steam, which then is partly used in the process and partly for CHP production (Barta et al., 2010b).

\section{Methodology}

After literature review and data collection, four types of biofuel production plants were included in the study. For each of those four technology cases, the biofuel production costs were estimated. The analyses were done considering different EM conditions and different DHS conditions. As it was already mentioned (see section 1.1), the period analysed is between 2030 and 2040. However, variations of the EM prices during the analysed period were not considered in this study. Instead, the values of the prices for the year 2030 were used as input data during the whole period. 


\subsection{Development of future energy market scenarios for Sweden for the year 2030}

In order to perform sensitivity analyses of fuel prices and policy instruments, two future global EMSs for the year 2030, which have been developed by International Energy Agency (IEA) were used (IEA, 2011). The first scenario is based on the recent government policy commitments; it is known as "New Policies Scenario" (WEO-np). The second scenario is based on energy policies which according to the IEA would enable the $2^{\circ} \mathrm{C}$ target (more explained in Pachauri and Reisinger, 2007) to be reached at a reasonable cost. This scenario is known as the "450 Scenario" (WEO-450). Based on these two global EMSs, the energy (fossil fuel, electricity, biomass, biofuel and DH) prices on Swedish EM were calculated (Table 1) using the ENPAC tool (Energy Price and Carbon Balance tool). This tool has been developed by Axelsson et al. (2009; Axelsson and Harvey, 2010), and it has been used in a number of previous studies (e.g. Pettersson and Harvey, 2012; Heyne and Harvey, 2013; Difs et al., 2010).

Figure 2 gives an overview of the calculation procedure adopted in the ENPAC. The input data to the ENPAC tool were: the fossil fuel prices and the $\mathrm{CO}_{2}$ charges from the global EMSs, as well as financial support for transportation fuel produced from renewable energy sources (RES-T), and support for electricity produced from renewable energy sources (RES-E). The levels of those supports were assumed based on the average values for Europe. After the fossil fuel prices for Swedish EM were calculated, the "build" marginal technology (the term is explained in Ådahl and Harvey (2007)) for electricity production was determined. It was assumed that carbon capture and storage will still not be an economically attractive technology in 2030, so only two possible build margins were considered: coal condensing power (CCP) plants and natural gas combined cycle (NGCC) plants. The electricity prices were calculated considering the total generation cost in the marginal plants for a period of ten years, including investment costs and the present values of the plants (Axelsson et al. 2009; Axelsson and Harvey, 2010). 
While the gasoline and fossil diesel prices are determined by the crude oil price, the biofuel prices are determined by users' willingness to pay for it. In this study it was assumed that the users will be willing to pay for biofuel only if the final biofuel price at filling stations is not higher than the price of the fossil fuel replaced. The prices were not compared per litre, instead the fuel economies for different fuels $(\mathrm{kWh} / 100 \mathrm{~km})$ were considered. The gasoline price sets the prices for biogas and ethanol, while the fossil diesel price sets the prices for FTD and DME. When the gate selling prices were calculated (the prices that the biofuel producers would sell the biofuel), the prices at the filling stations were reduced by the costs for the transportation of the biofuels from the plants to the filling stations. As it was already mention, in this study it is assumed that the biofuel produced will be sold to the local filling stations (see section 1.1).

Since biomass is a limited resource, it will probably become even more subject to competition in the future. This would lead to an increased biomass price. By comparing different biomass users, based on the previously calculated electricity and biofuel prices, Axelsson and Harvey (2010) have identified two high-volume users with the greatest willingness to pay for the biomass: CCP plants where biomass can be co-fired, and plants for FTD production. In the future those users will probably be the price-setting groups for biomass (Axelsson and Harvey, 2010). When the biomass price was calculated, the cost for biomass transportation was included in the calculations. The assumed cost is $€ 4.2 / \mathrm{MWh}$, which corresponds to the cost for transportation of low grade biomass, $300 \mathrm{~km}$ by train or $500 \mathrm{~km}$ by boat (Börjesson and Gustavsson, 1996). For high grade biomass the distances are doubled.

DH prices are not determined only by the other prices in EMSs, but also by local conditions. After assuming that in Sweden in 2030 only negligible percentages of DH production would be based on fossil fuels, two different levels of DH prices are calculated: the price in large DHSs, which would be set by DH production BCHP plants (BCHP-DH price), and the price in small DHSs, which would be set by DH production in BHO boilers (BHO-DH price). 


\subsection{Economic and technical characteristics of the biofuel production plants and an overview}

of the calculation procedure

Four different types of biofuel production plants have been included in this study (Table 2).

Since the profitability of the biofuel production depends on the plant capacity as well as the factors previously mentioned in the introduction section (Faaij, 2006), all the plants have an input capacity of $300 \mathrm{MW}$. For each of these plants, the biofuel production costs were estimated considering the capital (investment) costs and the annual costs.

The investment costs for the plants have been adjusted to $€ 2010$ using the Chemical Engineering Plant Cost Index (CEPCI, 2010), and calculated from the data available in the referred studies using an overall scaling factor (R) of 0.7 (Remer and Chai, 1990) according to:

$$
\frac{\operatorname{Cost}_{a}}{\operatorname{Cost}_{b}}=\left(\frac{\text { Capacity }_{a}}{\text { Capacity }_{b}}\right)^{R},
$$

where Cost $\mathrm{a}_{\mathrm{a}}$ and Cost $_{\mathrm{b}}$ represent the cost of the base polygeneration plant and the cost of the new plant, respectively. Capacitya and Capacityb are the capacities of the base plant and the new plant, respectively. The study period was 10 years (from 2030 to 2040) while the assumed economic lifespans of the plants were 20 years. Due to this, the plants have some economic value after the end of the analysed period. These values were adjusted back to the beginning of the analysed period by an assumed discount rate and thereafter subtracted from the investment' costs (Henning, 1997).

The annual costs consist of raw material (biomass) costs, and operating and maintenance costs. While the material costs are always related to the output power, the operating and maintenance costs can be related to the output power or be a fixed cost (presented as a certain percentage of 
the investment costs). The revenues from the co-produced heat and electricity are also included in the annual costs as negative costs.

The ethanol production costs for the considered ethanol production plants differ significantly. Thus, in order to avoid confusion, the ethanol produced in the plant where upgraded biogas, heat and electricity are by-produced is denoted as Ethanol 1 from this point forward. The ethanol produced in the plant where only electricity and heat are by-produced is denoted as Ethanol 2.

\subsection{Sensitivity analyses performed in this study}

When doing sensitivity analyses of DHS conditions, two factors were considered as possibly influencing the profitability of the biofuel production: DH price (see section 3.1) and DH demand variation during the year. While the DH price may influence the revenues from the byproduced heat, the DH demand variation during the year may influence the annual operating time of the biofuel production plant. Thus, two different annual operating times were assumed in this study: $5000 \mathrm{~h}$ and $8000 \mathrm{~h}$.

The third sensitivity analysis performed in the study was of the discount rate. Two levels of discount rates were considered: $6 \%$ and $10 \%$.

\section{Results and discussion}

The profitability of biofuel production for four different biofuel production plants was analysed. The analyses were performed considering two EMSs: EMS WEO-np (the global EMS based on the recent government policy commitments) and EMS WEO-450 (which according to the IEA would enable the $2{ }^{\circ} \mathrm{C}$ target to be reached at a reasonable cost). When the biofuel production costs were calculated, the capital and the annual costs were taken into account. Sensitivity analyses of DH prices and discount rates were performed as well. 


\subsection{The profitability of biofuel production considering different EM conditions}

The profitability of biofuel production was discussed comparing the biofuel production costs with the gate biofuel prices (the prices in which the biofuel producers would sell the biofuel; see section 3.1). The gate biofuel prices were calculated assuming the final biofuel prices at the filling stations would be same as the prices of the replaced fossil fuel. Because of this, the price ratio between biomass (used as the feedstock for biofuel production) and crude oil (used as the feedstock for fossil diesel and gasoline production) has a crucial influence on the profitability of the biofuel production costs.

The profitability is shown to be lower when the prices are based on the EMS WEO-450 than when the prices are based on the EMS WEO-np. The main reason for this is that the higher $\mathrm{CO}_{2}$ charge (2.4 times higher) in EMS WEO-450 leads to a higher biomass price, due to a higher interest in biomass instead of coal use in the CCP plants (see section 3.1). The crude oil price is, on the other hand, much less influenced by $\mathrm{CO}_{2}$ charge. Thus, the price ratio between biomass and crude oil is about $45 \%$ higher in this EMS. As a consequence, (depending on the biofuel production technology, the $\mathrm{DH}$ price, the discount rate level and the annual operating time) the biofuel production costs are between $7 \%$ and $15 \%$ higher when the EMS WEO-450 is considered (Figures 3 and 4); at the same time the revenues from the sold biofuel (based on the gate biofuel prices) would be only between $1 \%$ and $3 \%$ higher.

The price ratios between biomass and $\mathrm{DH}$, and between biomass and electricity, also have an influence on the profitability of biofuel production. Higher DH and electricity prices lead to higher revenues from the heat by-produced and the electricity by-produced. Since the electricity efficiency is lower than the heat efficiency in all biofuel production plants included in this study (except in the FTD diesel production plant, where those two efficiencies are equal; 
see Table 2), the price ratio between biomass and electricity has a lesser influence on the profitability than the price ratio between biomass and $\mathrm{DH}$.

\subsection{The profitability of biofuel production for different technology cases}

The most profitable technology case analysed in this study is the plant where the upgraded biogas and the ethanol are produced (denoted as Ethanol 1 in Figures 3 and 4). This technology is a strong alternative in both EMSs. Because two different biofuels are produced at once in this plant, the biofuel production costs are actually the costs for production of the biofuel mix which consists of those two biofuels. From those biofuel production costs the Ethanol 1 production costs and the biogas production costs are calculated assuming that the ratio between them is the same as the ratio between their gate prices without the RES-T support included. The results (Figures 3 and 4) show that when the EMS WEO-np is considered, the biogas and the Ethanol 1 production costs are between $25 \%$ and $47 \%$ lower (depending on the DH price, the annual operating time and the discount rate level) than the biogas and ethanol gate prices that do not include the RES-T support. When the EMS WEO-450 is considered, this difference is between $18 \%$ and $41 \%$. The biogas and the Ethanol 1 production costs are more than $40 \%$ lower than the biogas and the ethanol gate prices that include RES-T support when the discount rate is $6 \%$, and more than $38 \%$ lower when the discount rate is $10 \%$. The highest profitability is found in the EMS WEO-np when a higher DH price and the lower discount rate level are assumed, and when the annual operating time is $8000 \mathrm{~h}$. In this case, the biofuel production costs are about $46 \%$ lower than the gate prices which do not include the RES-T support and approximately $60 \%$ lower than the gate prices which do include the RES-T support.

Compared to the Ethanol 1 production costs, the ethanol production without by-production of upgraded biogas (Ethanol 2 production) proves to be more expensive. Compared to the Ethanol 1 production costs, the Ethanol 2 production costs are between $28 \%$ and $43 \%$ higher when the 
heat by-produced is sold to a large DHS (where the DH price is set by DH production in BCHP plants) and between $7 \%$ and $29 \%$ higher when the heat co-produced is sold to a small DHS (where the $\mathrm{DH}$ price is set by $\mathrm{DH}$ production in $\mathrm{BHO}$ boilers); this depends on the discount rate level, the EMS and the annual operating time. In order to make it profitable to produce Ethanol 2, when the DH price is low and when the annual operating time is only $5000 \mathrm{~h}$, the RES-T support should be included. If the discount rate is $6 \%$, in the EMS WEO-np, the REST support should be $€ 2 / \mathrm{MWh}$ and in the EMS WEO-450 at least $€ 8.5 / \mathrm{MWh}$ (Figure 5). When the discount rate is $10 \%$ RES-T support should be $€ 7 / \mathrm{MWh}$ and $€ 13.5 / \mathrm{MWh}$ (Figure 6).

The Ethanol 1 and Ethanol 2 production costs calculated in this study can be compared with the ethanol production costs calculated by Barta et al. (2010b), who have considered the same technology cases for ethanol production with an annual operating time of $8000 \mathrm{~h}$. When Barta et al. (2010b) assumed a discount rate of $7 \%$, a DH price of $€ 27 / \mathrm{MWh}$ (similar to the BCHPDH price in the EMS WEO-np; Table 1), and an electricity price of $€ 87 / \mathrm{MWh}$ (similar to the electricity price which include RES-E support in the EMS WEO-np; Table 1), they found the Ethanol 1 production costs to be about $€ 0.36 / \mathrm{L}$ ( $€ 53 / \mathrm{MWh})$ and the Ethanol 2 production costs to be $€ 0.41 / \mathrm{L}$ (€61/MWh). The reason why the findings are not completely in line with the findings in the present study (where the Ethanol 1 and the Ethanol 2 production costs are $€ 52 / \mathrm{MWh}$ and $€ 68 / \mathrm{MWh}$, respectively; see Figure 3) is that the biomass prices and the discount rates assumed in those studies differ.

Due to higher biofuel efficiencies, compared to the Ethanol 2 production (Table 2), the biomass costs for production of $1 \mathrm{MWh}$ FTD or $1 \mathrm{MWh}$ DME are lower. However, because of the higher investment costs (Table 2) and the lower heat and electricity efficiencies (which consequently lead to lower revenues from the heat and electricity by-produced), FTD and DME productions are shown to be more expensive than Ethanol 2 production. Compared to the Ethanol 2 production costs, the FTD production costs are between $28 \%$ and $44 \%$ higher 
(depending on the discount rate level and the annual operating time) when the DH price is low, and between $54 \%$ and $93 \%$ higher when the DH price is high. Due to the fact that the Ethanol 1 production is followed by a lower heat by-production than the Ethanol 2 production, the differences between the FTD production costs and the Ethanol 1 production costs are less dependent on the DH price level. The FTD production costs are between $82 \%$ and $107 \%$ higher than the Ethanol 1 production costs, and between $53 \%$ and $75 \%$ higher than the biogas production costs; this difference depends on the annual operating time, the discount rate and the EM and DHS condition. The DME production is shown to be even less profitable than the FTD production. The DME production costs are shown to be between $91 \%$ and $130 \%$ higher compared to the Ethanol 1 production costs, between $61 \%$ and $96 \%$ higher compared to the biogas production costs and between $48 \%$ and $97 \%$ higher than the Ethanol 2 production costs. Besides the higher production costs, the reason why the FTD and DME productions are less profitable than the Ethanol 1, Ethanol 2, and biogas productions is that the FTD and DME gate prices are lower than the ethanol and biogas gate prices (Table 1); this makes revenues from the FTD sale and the DME sale lower.

Figures 5 and 6 show the RES-T support required in order to make the biofuel productions profitable. This RES-T support varies within a wide range between $€ 2 / \mathrm{MWh}$ and $€ 79 / \mathrm{MWh}$, depending on the biofuel produced, the discount rate and the EM and DHS conditions. The results show that the DME production is profitable only if the RES-T support is higher than the support suggested in this study ( $€ 26 / \mathrm{MWh}$; see Table 1$)$. In order to make the DME production profitable when the operating time of the plant is $5000 \mathrm{~h}$ annually, the RES-T support should be more than two times higher than the support suggested if the discount rate is $6 \%$, and about 3 times higher if the discount rate is $10 \%$. The only case where the FTD production is shown to be profitable if the RES-T support is $€ 26 / \mathrm{MWh}$, is when the EMS WEO-np is considered and when the annual operating time is $8000 \mathrm{~h}$. Likewise, the only case where the Ethanol 2 
production is not profitable without the RES-T support included, is when the annual operating time is $5000 \mathrm{~h}$ and when at the same time the DH price is low. In this case the RES-T support required varies within a wide range between $€ 2 / \mathrm{MWh}$ and $€ 13 / \mathrm{MWh}$.

The increase of the discount rate from $6 \%$ to $10 \%$ is shown not to have a large influence on the biofuel production costs for the technology cases included in this study. The plant which shows the largest sensitivity to the discount rate increase is the plant where the biogas by-produced is not upgraded but instead used for CHP production. This is despite the fact that the investment cost for this plant is lower than the investment cost for FTD and DME production plants. The reason for this is a lower total biofuel efficiency compared with the other biofuel production plants included in the study. Thus, when the discount rate increases from $6 \%$ to $10 \%$, the Ethanol 2 production costs increase between $4 \%$ and $6.8 \%$ (depending on the EM and DHS conditions), while the Ethanol 1, biogas and FTD production increase only between $2.2 \%$ and $4.4 \%$. Likewise, the DME production costs increase between $3.6 \%$ and $5 \%$.

\subsection{Sensitivity analyses of DHS conditions}

Sensitivity analyses were performed assuming a discount rate of $6 \%$.

The technology cases analysed show the different sensitivities to the DH price level and to the annual operating time (Figure 7). While the sensitivity to the DH price level depends on the heat efficiency of the plant, the sensitivity to the annual operating time depends on the investment costs and the total by-product (heat and electricity) efficiency.

Due to the fact that the Ethanol 2 production plant has the highest heat efficiency compared to the other technology cases (see Table 2), the Ethanol 2 production costs show the highest sensitivity to the DH price level. Thus, the benefits of introducing such a biofuel production into a DHS are most obvious. If the RES-T support is included and the discount rate is low 
$(6 \%)$, the Ethanol 2 production is profitable even without revenues from the heat co-produced in all analysed cases, except when the EMS WEO-450 is considered and the annual operating time is $5000 \mathrm{~h}$ (Figure 7). In order to make the Ethanol 2 production profitable in this case, the DH price should be $€ 11 / \mathrm{MWh}$ or higher. For very low DH prices (lower than $€ 4 / \mathrm{MWh}$ ), Ethanol 2 production costs are even shown to be higher than the FTD production costs. If the operating time of the plant is $8000 \mathrm{~h}$ annually, introducing Ethanol 2 production into a DHS would lead to a $34 \%$ lower Ethanol 2 production cost if the DH price were set by BCHP; the Ethanol 2 production cost would be about $51 \%$ lower (depending on the EMS) if the DH price were set by BHO boilers. When the annual operating time is only $5000 \mathrm{~h}$, the decrease of the Ethanol 2 production costs after introduction into a DHS with a low DH price is about $28 \%$, and if the DH price in the DHS is high, it is about $43 \%$.

The simultaneous biogas and ethanol (Ethanol 1) productions are profitable for all EM and DHS conditions even without revenues from the heat co-produced (Figure 7). Introduction of such a biofuel production into a DHS guarantees between $24 \%$ and $28 \%$ (depending on the EMS and annual operating time) lower production costs when the DH price is high, and between $16 \%$ and $19 \%$ when the $\mathrm{DH}$ price is low.

Compared to the simultaneous biogas and ethanol production, and especially compared to the Ethanol 2 production, the FTD production and the DME production are characterised by lower sensitivities to the DH price level and to the annual operating time. For all analysed EM and DHS conditions, the DME production costs are shown to be highest compared to the other technology cases included in the study. As previously mentioned, for low DH prices (lower than $€ 4 / \mathrm{MWh}$ ), the FTD production costs are lower than the Ethanol 2 production costs. However, despite this, even in this case the FTD production is less profitable than the Ethanol 2 production due to the lower FTD gate prices. Because of the low heat efficiencies, it could be easier to find a DHS that can accept the entire amount of heat by-produced during the FTD and 
DME production, but on the other hand, the benefits of introducing FTD and DME production into a DHS would be low. Even if the DH price were high (set by $\mathrm{DH}$ production in $\mathrm{BHO}$ boilers), the FTD and the DME production costs would decrease by less than $10 \%$ if the plants were introduced into the DHS.

The results presented in this study are based on four different biofuel production technologies which are still in development. Further development of these technologies may have a high influence on both economic and technical characteristics of the plants. There is also a high degree of uncertainty regarding the future EM conditions. In order to get more reliable results, more biofuel production technologies and more EMSs should be considered in future studies. Furthermore, the introduction of biofuel production into a DHS should not be considered only by assessing the profitability. If such strategy has the potential to contribute to a sustainable development of the TSs, the policy measures should be included in order to make this strategy profitable. A need to replace old DH production plants in an existing DHS can make the investments in biofuel production plants more profitable. Thus, in the second part of this study (Djuric Ilic et al., 2014) an analysis of how the economic characteristics of a DHS and how the energy use/by-produced in a DHS would be changed if DH producers were to invest in largescale biofuel production instead of CHP production in the future was performed. Stockholm's DHS was used as a case study. In this article it was also discussed how the local biofuel production would affect the biofuel percentage of the total fuel used in Stockholm's TS.

\section{Conclusion}

Biofuel production through polygeneration with heat as one of the by-products, implies a possibility for integration of biofuel production into DHSs. This may have effects on both DH production costs and biofuel production costs. In this article, the effects on the biofuel production costs were analysed considering four different technology cases for biofuel 
production and different EM and DHS conditions. The EMSs considered in this study are: EMS based on the recent government policy commitments (EMS WEO-np) and EMS which according to the IEA would enable the $2{ }^{\circ} \mathrm{C}$ target to be reached at a reasonable cost (EMS WEO-450).

With a heat efficiency of 0.44 and an electricity efficiency of 0.12 , the ethanol production during which the raw biogas co-produced is directly used for CHP production (Ethanol 2 in Figure 7), shows a high sensitivity to the $\mathrm{DH}$ price level and the annual operating time. Introduction of such a plant into a DHS (under the EM conditions assumed in this study, and when the discount rate is $6 \%$ ) guarantees between $28 \%$ and $52 \%$ lower biofuel production costs depending on the $\mathrm{DH}$ price level. In order to make ethanol production in such a plant profitable when the RES-T support is not included, the DH price must be high (set by DH production in $\mathrm{BHO}$ boilers) or the annual operating time must be $8000 \mathrm{~h}$ or higher.

On the other hand, when the raw biogas co-produced during the ethanol production is upgraded and sold as fuel for vehicles, the ethanol production costs are much lower. This is despite the lower heat and electricity efficiencies which lead to lower revenues from those by-products per MWh of biofuel produced. The main reason why the ethanol production costs are lower in this case is that there is a higher total biofuel (ethanol + biogas) efficiency which leads to lower biomass costs per MWh of the biofuel produced. The ethanol and biogas production in such a plant are profitable even in the worst case scenario (when the RES-T support is not included, when the discount rate is $10 \%$, when the $\mathrm{DH}$ price is low, and when the annual operating time is $5000 \mathrm{~h}$ ). Under the assumed EM and DHS conditions and when the discount rate is low (6\%), the introduction of this biofuel production plant into a DHS would result in between $16 \%$ and $28 \%$ lower biofuel production costs. 
The FTD and DME productions are shown to be profitable only with high RES-T support. The investment costs for those plants are more capital intense compared to the other two biofuel production plants included in the study. Moreover, due to the low heat and electricity efficiencies, the revenues from heat and electricity by-produced per MWh of biofuel produced are low, which makes the FTD and DME production costs high. The analysed FTD and DME production technologies may still be interesting for $\mathrm{DH}$ producers as an investment alternative, because of the lower heat efficiency, which makes it easier to find a DHS that can accept the entire amount of heat by-produced. However, at the same time, the introduction of FTD or DME production into DHSs would not result in any noticeable economic benefits. In the best case scenario (when the DH price is high, when the discount rate is $6 \%$, when the annual operating time is $8000 \mathrm{~h}$, and when EMS WEO-np is considered) the FTD production costs would be reduced by $6 \%$ and the DME production costs would be reduced by $9 \%$.

The introduction of biofuel production into DHSs is less profitable when the EMS WEO-450 is considered. One reason for this is that in the EMS WEO-450, the price ratio between biomass (used as feedstock for biofuel production) and crude oil (influences the gate biofuel prices; see section 3.1) is $45 \%$ higher than in the EMS WEO-np. Furthermore, the price ratios between biomass and DH are also higher in the EMS WEO-450, which results in higher ratio between the raw material (biomass) costs and the revenues from the heat co-produced. An increase of the discount rate from $6 \%$ to $10 \%$ does not have a significant influence on the biofuel production costs. Depending on the biofuel production plant, and on the EM and DHS conditions, when the discount rate increases from $6 \%$ to $10 \%$, the biofuel production costs increase within a range from $2.2 \%$ to $6.8 \%$. 


\section{Acknowledgements}

This research was conducted under the auspices of the Energy Systems Programme at Linköping University, which is financially supported by the Swedish Energy Agency. A part of the research was conducted within the project Sustainable Cities in a Backcasting Perspective, which is financially supported by the Swedish District Heating Association, Blekinge Institute of Technology and Linköping University. The financial support is gratefully acknowledged. The authors would like to express their gratitude to Dr. Dag Henning (of Optensys Energianalys AB) for his support and valuable comments.

\section{References}

Agostingo, F., Ortega, E., 2013. Energetic-environmental assessment of a scenario for Brazilian cellulosic ethanol. J. Clean. Prod., 47, 474-489.

Axelsson, E., Harvey, S., Berntsson, T., 2009. A tool for creating energy market scenarios for evaluation of investments in energy intensive industry. Energy, 34(12), 2069-2074.

Axelsson, E., Harvey, S., 2010. Scenarios for assessing profitability and carbon balances of energy investments in industry. AGS Pathways report 2010:EU1. The Alliance for Global Sustainability, Gothenburg, Sweden.

Balat, M., Balat, M., Kirtay, E., Balat, H., 2009. Main routes for the thermo-conversion of biomass into fuels and chemicals. Part 2: Gasification systems. Energy Convers. Manag., 50(12), 3158-3168.

Barta, Z., Kovacs, K., Reczey, K., Zacchi, G., 2010a. Process design and economics of on-site cellulase production on various carbon sources in a softwood-based Ethanol plant. Enzyme Res., doi:10.4061/2010/734182. 
Barta Z., Reczey K., Zacchi G., 2010b. Techno-economic evaluation of stillage treatment with anaerobic digestion in a softwood-to-ethanol process. Biotechnol. Biofuels, 3(21), 1-11.

Börjesson, P., Gustavsson, L., 1996. Regional production and utilization of biomass in Sweden. Energy, 21(9), 747-764.

CEPCI, 2010. Chemical Engineering Plant Cost Index. Available at: www.che.com/pci (Accessed July 7, 2010)

Difs, K., Wetterlund, E., Trygg, L., Söderström, M., 2010. Biomass gasiffication opportunities in a district heating system. Biomass and Bioenergy, 34(5), 637-651.

Djuric Ilic, D., Dotzauer, E., Trygg, L., 2012. District heating and ethanol production through polygeneration in Stockholm. Appl. Energy, 91(1), 214-221.

Djuric Ilic, D., Dotzauer, E., Trygg, L., Broman, G., 2014. Integration of biofuel production into district heating - Part II: an evaluation of the district heating production costs using Stockholm as a case study. J. Clean. Prod. in review.

European Commission, 2008. 2020 by 2020: Europe's climate change opportunity, COM (2008) 30 final. European Commission, Brussels, Belgium. Available at: ec.europa.eu/energy/strategies/2008/2008_01_climate_change_en.htm (Accessed January 9, 2014).

European Commission, 2011. Roadmap to a Single European Transport Area- Towards a Competitive and Resource Efficient Transport System. COM (2011) 144 final. European Commission, $\quad$ Brussels, $\quad$ Belgium. Available at: ec.europa.eu/transport/themes/strategies/2011_white_paper_en.htm (Accessed January 9, 2014). 
Faaij, A.P.C., 2006. Bio-energy in Europe: changing technology choices. Energy Policy 34(3), $322-342$.

Fahlén, E., Ahlgren, E.O., 2009. Assessment of integration of different biomass gasification alternatives in a district-heating system. Energy, 34(12), 2184-2195.

Gonela, V., Zhang, J., 2013. Design of the optimal industrial symbiosis system to improve bioethanol production. J. Clean. Prod. 64(1), 513-534.

Gunnarsson, I., 2011. The GoBiGas project - Efficient transfer of biomass to bio-SNG of high quality. Presented at SGC International Seminar on Gasification, Malmö, Sweden, October 7, 2011.

Hellsmark, H., 2010. Unfolding the formative phase of gasified biomass in the European Union - The role of system builders in realising the potential of second-generation transportation fuels from biomass. Ph.D. thesis. Chalmers University of Technology, Gothenburg, Sweden. Dissertation No. 3159.

Henning, D., 1997. MODEST-An energy-system optimisation model applicable to local utilities and countries. Energy 22(12), 1135-1150.

Heyne, S., Harvey, S., 2013. Assessment of the energy and economic performance of second generation biofuel production processes using energy market scenarios. Applied Energy 101, 203-212.

Hofbauer, H., Rauch, R., Bosch, K., Koch, R., Aichernig, C., Tremmel, H., Voigtlaender, K., Koch, R., Lehner, R., 2003. Biomass CHP plant Guessing - Asuccess story, in: Bridgwater, A.V. (Ed.), Pyrolysis and Gasification of Biomass and Waste. CPL Press, Newbury, UK, pp. 527-536. 
IEA (International Energy Agency), 2011. World Energy Outlook 2011. Available at: www.worldenergyoutlook.org (Accessed January 9, 2014).

Leduc, S., Schwab, D., Dotzauer, E., Schmid, E., Obersteiner, M., 2008. Optimal location of wood gasification plants for methanol production with heat recovery. Int. J. Energy Res., 32, $1080-1091$.

Leduc, S., Schmid, E., Obersteiner, M., Riahi, K., 2009. Methanol production by gasification using a geographically explicit model. Biomass and Bioenergy, 33(5), 745-751.

Leduc, S., Lundgren, J., Franklin, O., Dotzauer, E., 2010. Location of a biomass based methanol production plant: A dynamic problem in northern Sweden. Applied Energy, 87(1), $68-75$.

van der Meijden, C., Bergman, P., van der Drift, A., Vreugdenhil, B., 2010. Preparations for a 10 MWth bio-CHP demonstration based on the MILENA gasification technology. Presented at the 18th European Biomass Conference and Exhibition, Lyon, France, May 3-7, 2010.

Nguyen, T.L.T., Gheewala, S.H., Sagisaka, M., 2010. Greenhouse gas savings potential of sugar cane bio-energy systems. J. Clean. Prod., 18(5), 412-418.

Pachauri, R.K., Reisinger, A., 2007. Climate Change 2007: Synthesis Report, Intergovernmental Panel on Climate Change. Available at: www.ipcc.ch/publications_and_data/publications_ipcc_fourth_assessment_report_synthesis_ report.htm (Accessed September 25, 2013).

Piccolo, C., Bezzo, F., 2009. A techno-economic comparison between two technologies for bioethanol production from lignocellulose. Biomass and Bioenergy, 33(3), 478-491. 
Pereira, C.L.F., and Ortega, E., 2010. Sustainability assessment of large-scale ethanol production from sugarcane. J. Clean. Prod., 17(10), 896-899.

Pettersson, K., Harvey, S., 2012. Comparison of black liquor gasification with other pulping biorefinery concepts - Systems analysis of economic performance and $\mathrm{CO}_{2}$ emissions. Energy, 37(1), 136-153.

Ponton, J.W., 2009. Biofuels: Thermodynamic sense and nonsense. J. Clean. Prod., 18(1), 7782.

Porzio, G.F., Prussi, M., Chiaramonti, D., Pari, L., 2012. Modelling lignocellulosic bioethanol from poplar: estimation of the level of process integration, yield and potential for co-products. J. Clean. Prod., 34, 66-75.

Pröll, T., Rauch, R., Aichernig, C., Hofbauer, H., 2007. Fluidized bed steam gasification of solid biomass - Performance characteristics of an 8 MWth combined heat and power plant. International Journal of Chemical Reactor Engineering Vol. 5: A54.

Remer, D.S., Chai, L.H., 1990. Design cost factors for scaling-up engineering equipment. Chem. Eng. Prog., 86(8), 77-82.

Renouf, M.A., Pagan, R.J., Wegener, M.K., 2013. Bio-production from Australian sugarcane: an environmental investigation of product diversification in an agro-industry. J. Clean. Prod., 39, 87-96.

Sassner, P., Galbe, M., Zacchi, G., 2008. Techno-economic evaluation of bioethanol production from three different lignocellulosic materials. Biomass Bioenergy, 32(5), 422-430. 
Sassner, P., Zacchi, G., 2008. Integration options for high energy efficiency and improved economics in a wood-to-ethanol process. Biotechnology for Biofuels 1:4 doi:10.1186/17546834-1-4.

SEA, 2010. Energy in Sweden 2010. Swedish Energy Agency (SEA), Eskilstuna, Sweden. Available at:

http://webbshop.cm.se/System/TemplateView.aspx?p=Energimyndigheten\&view=default\&id =b4cea7b00212456b9bdbdbe47a009474 (Accessed January 9, 2014).

Skarlis, S., Kondili, E., Kaldellis, J.K., 2012. Small-scale biodiesel production economics: a case study focus on Crete Island. J. Clean. Prod., 20(1), 20-26.

Söderström, J., Galbe, M., Zacchi, G., 2005. Separate versus simultaneous saccharification and fermentation of two-step steam pretreated softwood for Ethanol production. J. Wood Chem. Technol., 25(3), 187-202.

Sotoft, F.L., Rong, B.G., Christensen, K.V., Norddahl, B., 2010. Process simulation and economical evaluation of enzymatic biodiesel production plant. Bioresource Tehcnology, 101(14), 5266-5274.

Starfelt F, Daianova L, Yan J, Thorin E, Dotzauer E., 2009. Increased renewable electricity production in combined heat power plants by introducing ethanol production. In: Proceeding of the first international conference on applied energy (ICAE09). Hong Kong, China; 2009 January $5-7$.

Starfelt F, Thorin E, Dotzauer E, Yan J., 2010. Performance evaluation of adding ethanol production into an existing combined heat and power plant. Bioresour Technol, 101(2), 613-608. 
Thunman, H., Seemann, M.C., 2009. First experiences with the new Chalmers gasifier, in: Proceedings of the 20th International Conference on Fluidized Bed Combustion, Xi'an, China, May 18-20, 2009, pp. 659-663.

Wang, Y., Fan, W., Liu, Y., Zeng, Z., Hao, X., Chang, M., Zhang, C., Xu, Y., Xiang, H., Li, Y., 2008a. Modeling of the Fischer-Tropsch synthesis in slurry bubble column reactors. Chem. Eng. Process., 47(2), 222-228.

Wang, L., Weller, C.L., Jones, D.D., Hanna, M.A., 2008b. Contemporary issues in thermal gasification of biomass and its application to electricity and fuel production. Biomass Bioenergy, 32(7), 573-581.

Wetterlund, E., 2010. Optimal localization of biofuel production on a European scale. International institute for applied systems analysis, Laxenburg, Austria, Interim report, IR-10-020.

Wetterlund, E., Söderström, M., 2010. Biomass gasification in district heating systems - The effect of economic energy policies. Appl. Energy, 87(9), 2914-2922.

Wetterlund, E., Pettersson, K., Harvey, S., 2011. Systems analysis of integrating biomass gasification with pulp and paper production - Effects on economic performance, $\mathrm{CO}_{2}$ emissions and energy use. Energy, 36(2), 932- 941.

Wetterlund, E., 2012. System studies of forest-based biomass gasification. Ph.D. thesis. Linköping University, Linköping, Sweden. Dissertation No. 1429.

Wetterlund, E., Leduc, S., Dotzauer, E., Kindermann, G., 2012. Optimal localisation of biofuel production on European scale. Energy, 41(1), 462-472. 
Wingren, A., Gable, M., Zacchi, G., 2003. Techno-economic evaluation of producing ethanol from softwood: comparison of SSF and SHF and identification of bottlenecks. Biotechnology Prog., 19(4), 1109-1117.

Ådahl, A., Harvey, S., 2007. Energy efficiency investments in Kraft pulp mills given uncertain climate policy. Int J Energy Res, 31(5), 486-505.

\section{Figures}

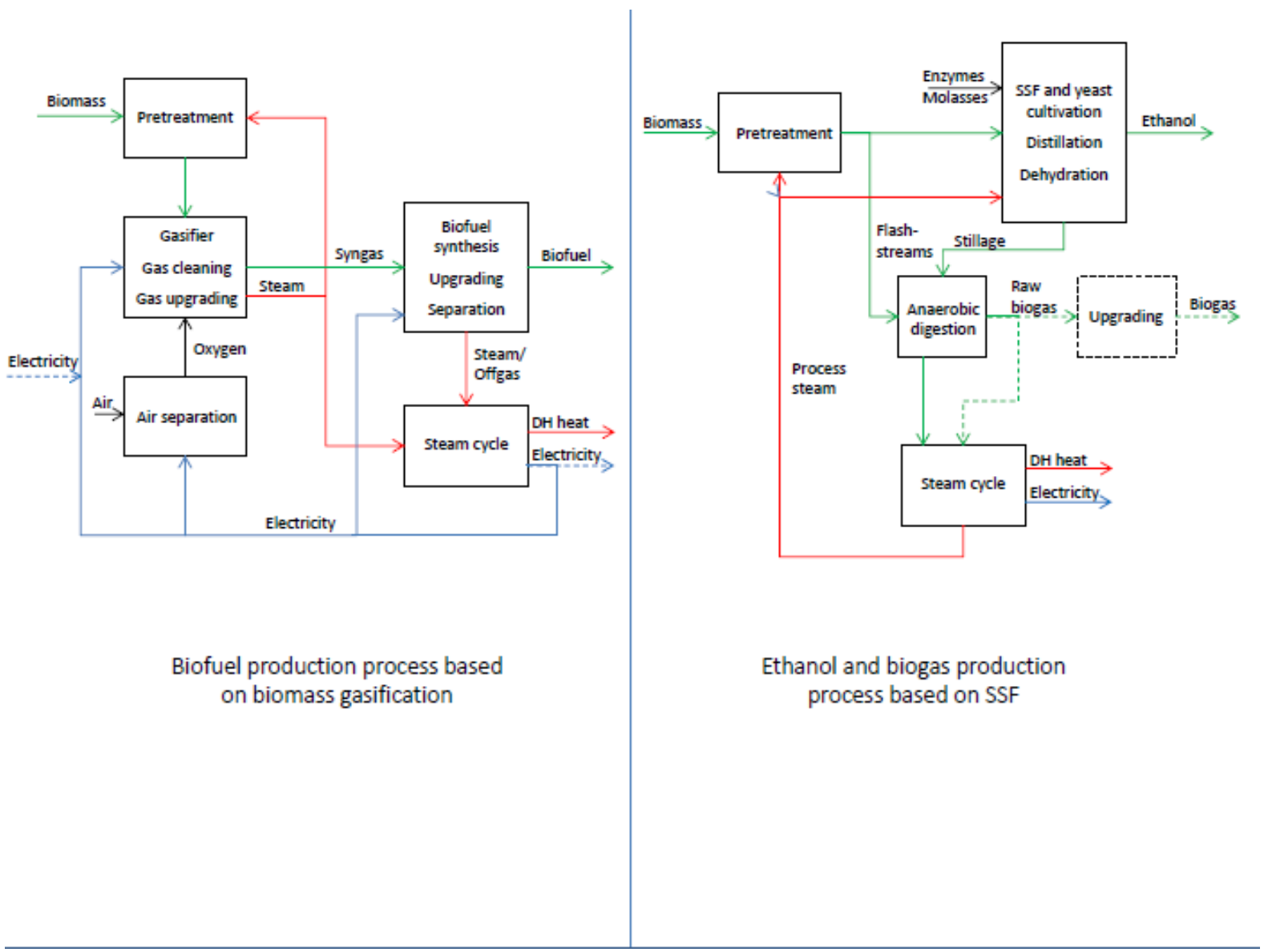

Figure 1. Schematic overview of biofuel (in the present study DME and FTD) production based on biomass gasification (Wetterlund, 2012) and of ethanol and biogas production based on SSF. 


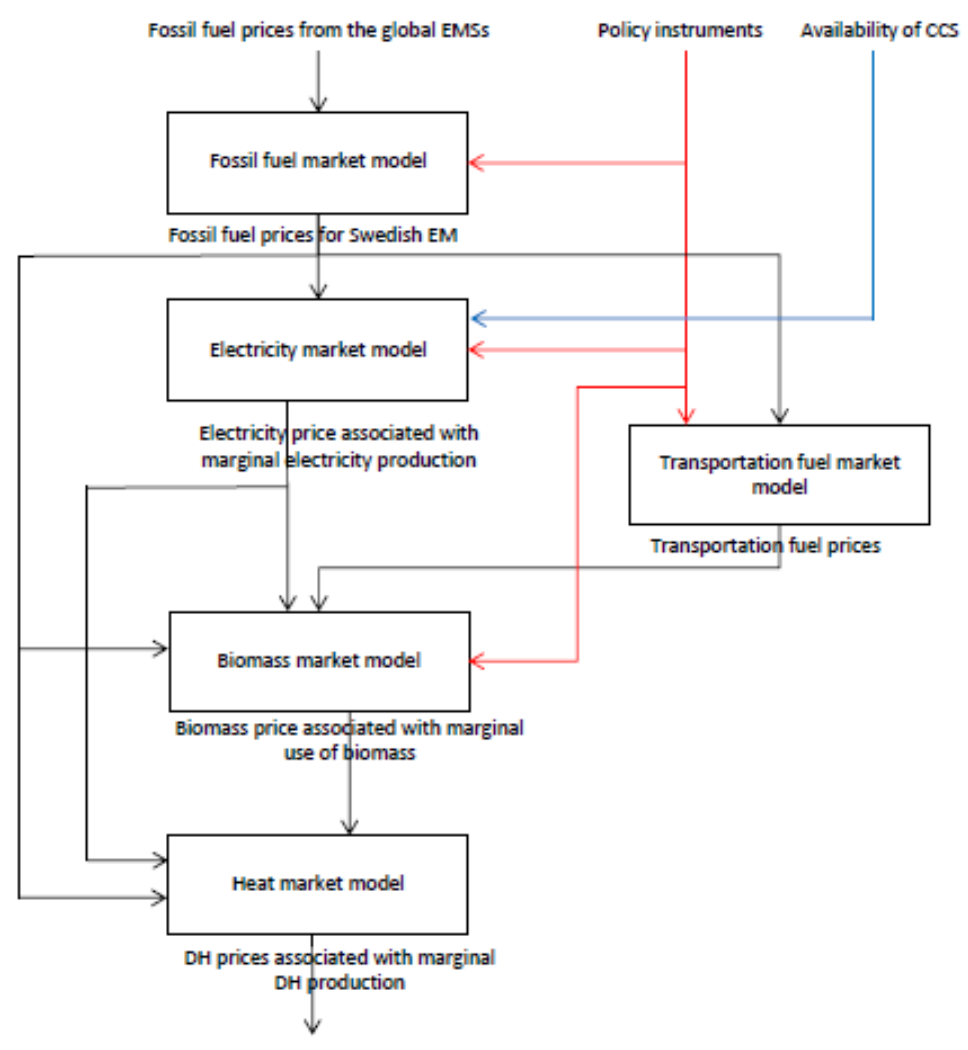

Figure 2. An overview of the calculation flow in the ENPAC tool. 


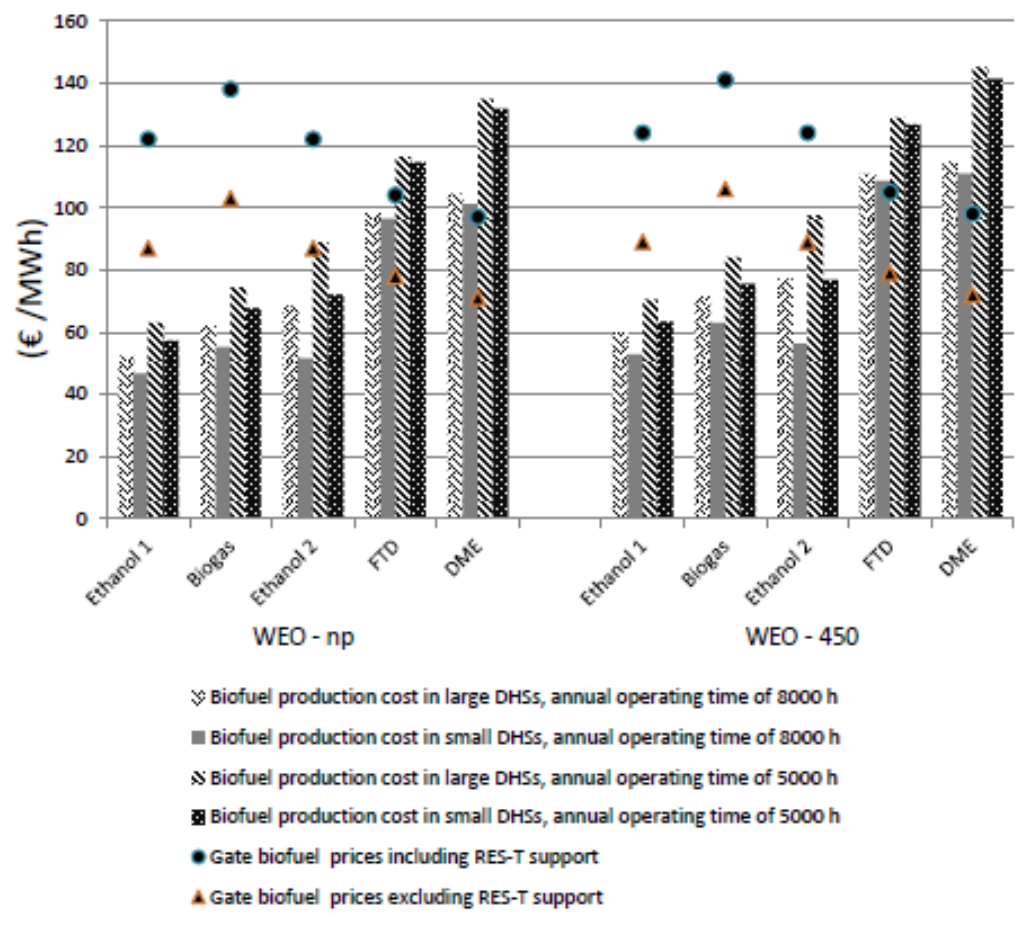

Figure 3. Biofuel production costs for different polygeneration plants considering different EM conditions and a discount rate of $6 \%$ ("Ethanol 1" - the ethanol produced in the plant where upgraded biogas, heat and electricity are by-produced; "Ethanol 2" - the ethanol produced in the plant where only electricity and heat are by-produced). 


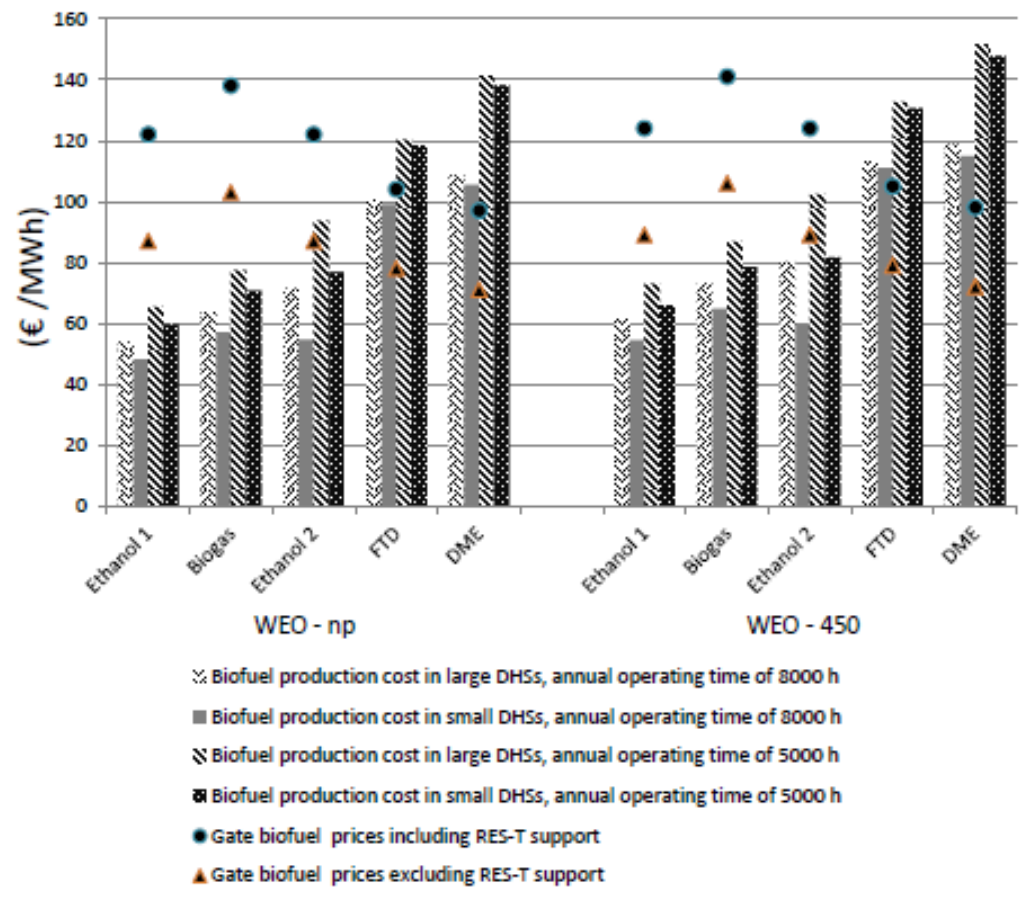

Figure 4. Biofuel production costs for different polygeneration plants considering different EM conditions and a discount rate of $10 \%$ ("Ethanol 1" - the ethanol produced in the plant where upgraded biogas, heat and electricity are by-produced; "Ethanol 2" - the ethanol produced in the plant where only electricity and heat are by-produced). 


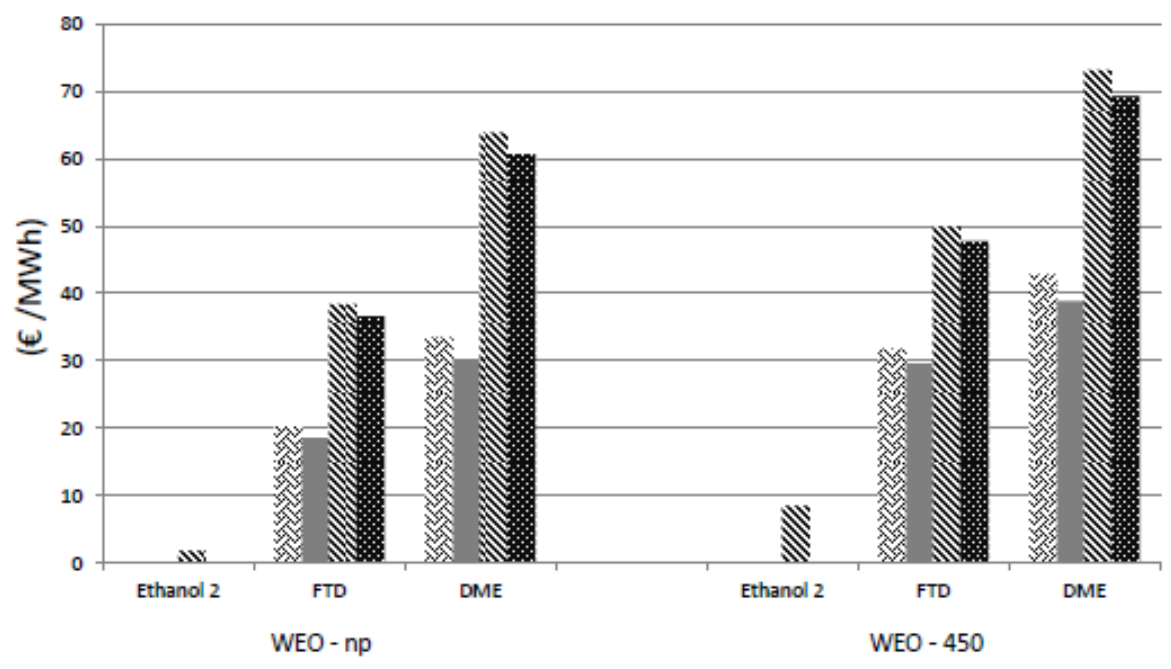

« RES-T support required when the biofuel production introduced into large DHSs, annual operating time of $8000 \mathrm{~h}$ ERES-T support required when the biofuel production introduced into small DHSs, annual operating time of $8000 \mathrm{~h}$ NRES-T support required when the biofuel production introduced into large DHSs, annual operating time of $5000 \mathrm{~h}$ \$RES-T support required when the biofuel production introduced into small DHSs, annual operating time of $5000 \mathrm{~h}$

Figure 5. RES-T support required to make the investments in the biofuel production plants profitable considering different EM conditions and a discount rate of $6 \%$ ("Ethanol 2" - the ethanol produced in the plant where only electricity and heat are by-produced). 


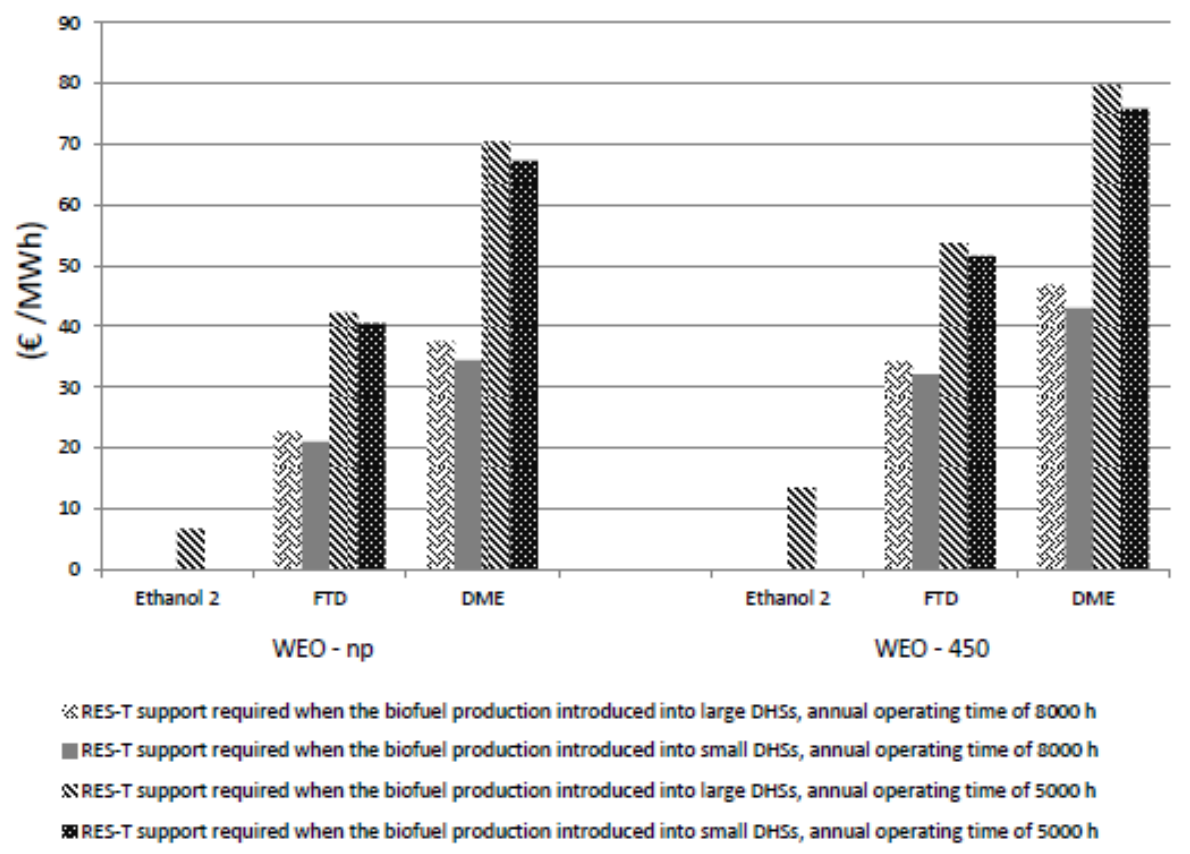

Figure 6. RES-T support required to make the investments in the biofuel production plants profitable considering different EM conditions and a discount rate of $10 \%$ ("Ethanol 2" - the ethanol produced in the plant where only electricity and heat are by-produced). 

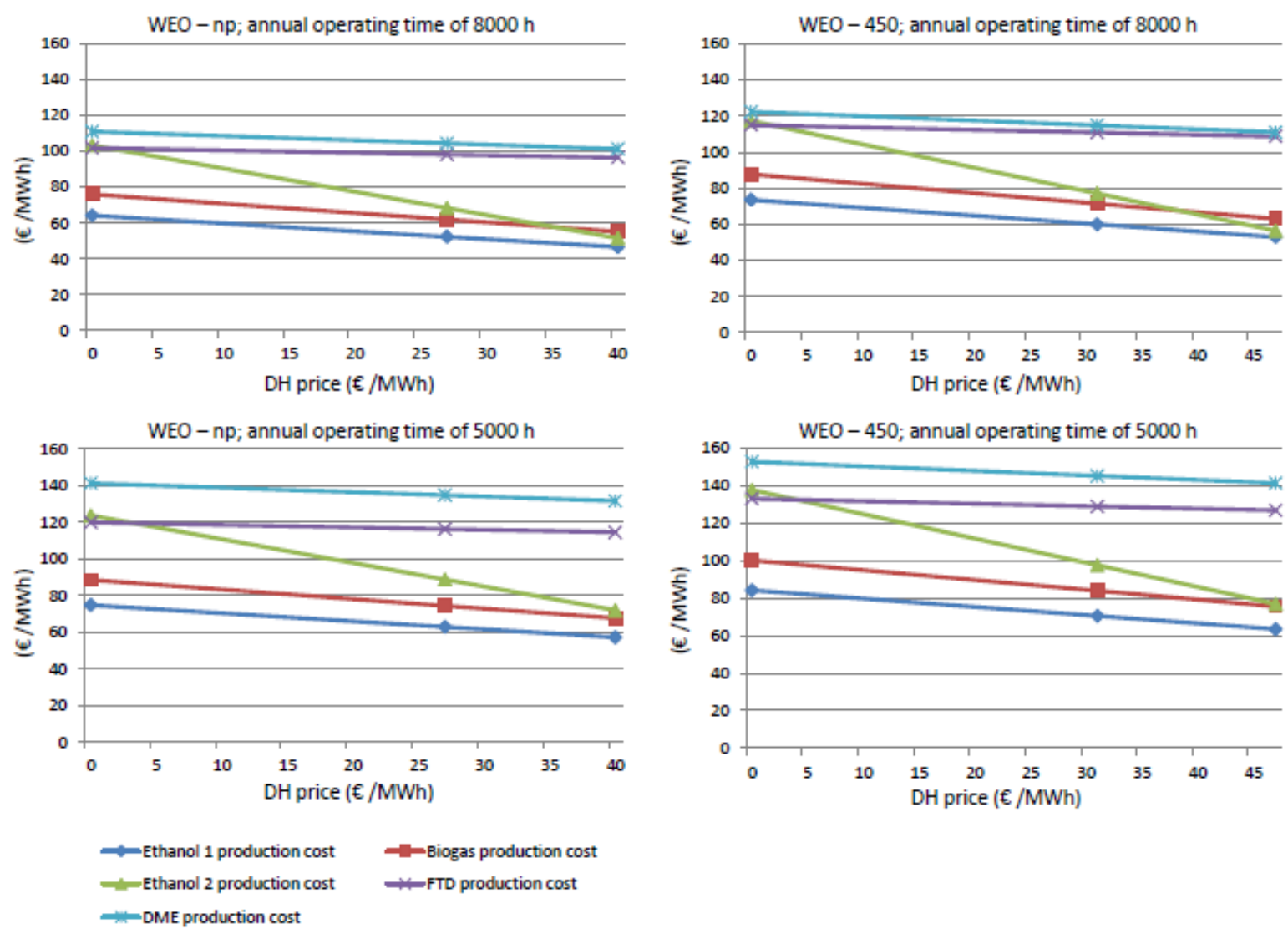

Figure 7. Biofuel production costs as a function of DH prices considering different EM conditions and a discount rate of $6 \%$ ("Ethanol 1" - the ethanol produced in the plant where upgraded biogas, heat and electricity are by-produced; "Ethanol 2" - the ethanol produced in the plant where only electricity and heat are by-produced). 
Table 1. EMSs for the year 2030.

\begin{tabular}{|c|c|c|c|}
\hline EMSs & & WEO-np & WEO-450 \\
\hline \multicolumn{4}{|c|}{ Input data } \\
\hline \multicolumn{4}{|c|}{ World market fossil fuel prices excluding $\mathrm{CO}_{2}$ charges $(€ / \mathrm{MWh})$} \\
\hline Crude oil & & 55 & 46 \\
\hline Natural gas & & 34 & 28 \\
\hline Coal & & 11 & 7 \\
\hline \multicolumn{4}{|c|}{ Energy policy instruments } \\
\hline $\mathrm{CO}_{2}$ charge & $(€ / \mathrm{t})$ & 30 & 72 \\
\hline RES-E support ${ }^{a}$ & $(€ / \mathrm{MWh})$ & 20 & 20 \\
\hline RES-E quota & $(\%)$ & 20 & 20 \\
\hline RES-T support ${ }^{\mathrm{b}}$, "diesel fuels" & $(€ / \mathrm{MWh})$ & 26 & 26 \\
\hline RES-T support, "petrol fuels" & $(€ / \mathrm{MWh})$ & 35 & 35 \\
\hline \multicolumn{4}{|c|}{ Output data } \\
\hline \multicolumn{4}{|c|}{ Fossil fuel prices on Swedish EM including $\mathrm{CO}_{2}$ charges $(€ / \mathrm{MWh})$} \\
\hline Light fuel oil & & 74 & 75 \\
\hline Heavy fuel oil & & 56 & 61 \\
\hline Natural gas & & 46 & 49 \\
\hline Coal & & 23 & 35 \\
\hline \multicolumn{4}{|c|}{ Electricity market } \\
\hline Build margin & & $\mathrm{CCP}^{\mathrm{c}}$ & NGCC \\
\hline Electricity price & $(€ / \mathrm{MWh})$ & 67 & 86 \\
\hline \multicolumn{4}{|c|}{ Gate biofuel prices including RES-T support (€/MWh) } \\
\hline Ethanol & & 122 & 124 \\
\hline FTD & & 104 & 105 \\
\hline DME & & 97 & 98 \\
\hline Biogas & & 138 & 141 \\
\hline \multicolumn{4}{|c|}{ Biomass market } \\
\hline Marginal use of biomass & & FTD $^{d}$ production & $\mathrm{CCP}$ \\
\hline Low grade biomass & $(€ / \mathrm{MWh})$ & 33 & 41 \\
\hline High grade biomass & $(€ / M W h)$ & 47 & 57 \\
\hline \multicolumn{4}{|c|}{ DH market } \\
\hline BCHP-DH price & $(€ / M W h)$ & 27 & 31 \\
\hline BHO-DH price & $(€ / \mathrm{MWh})$ & 40 & 47 \\
\hline
\end{tabular}

${ }^{a}$ Support for electricity produced from renewable energy sources.

${ }^{\mathrm{b}}$ Support for transportation fuel produced from renewable energy sources.

${ }^{\mathrm{c}}$ Coal condensing power.

${ }^{\mathrm{d}}$ Fischer-Tropsch diesel. 
Table 2. Economic and technical characteristics of the biofuel production plants.

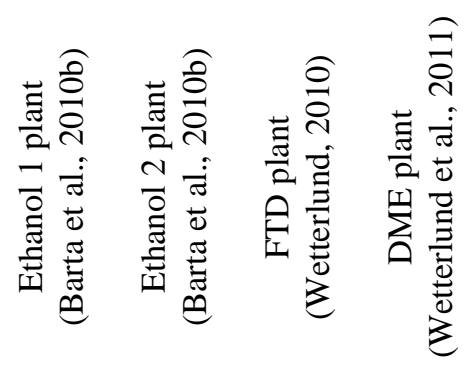

\begin{tabular}{|c|c|c|c|c|c|}
\hline \multicolumn{6}{|c|}{ Efficiency } \\
\hline \multicolumn{2}{|c|}{ Electricity } & 0.05 & 0.12 & 0.06 & - \\
\hline \multicolumn{2}{|c|}{ Biofuel 1} & 0.34 & 0.34 & 0.45 & 0.62 \\
\hline \multicolumn{2}{|c|}{ Biofuel $2^{\text {a }}$} & 0.25 & - & - & - \\
\hline \multicolumn{2}{|c|}{ Heat } & 0.28 & 0.44 & 0.06 & 0.15 \\
\hline \multicolumn{6}{|c|}{ Economic characteristics } \\
\hline Base plant capacity & $\left(\mathrm{MW}_{\text {input }}\right)$ & $300^{b}$ & $300^{\mathrm{b}}$ & $300^{\mathrm{c}}$ & $300^{d}$ \\
\hline \multirow{2}{*}{$\begin{array}{l}\text { Base investment cost } \\
\text { Spec. investment cost }\end{array}$} & $(€$ million $)$ & 277 & 289 & 304 & 320 \\
\hline & $\left(€ / \mathrm{kW}_{\text {input }}\right)$ & - & - & - & 1280 \\
\hline \multirow{2}{*}{$\begin{array}{l}\text { Fixed and variable } \\
\text { operating and } \\
\text { maintenance costs }\end{array}$} & $\begin{array}{l}\text { (\% of the total } \\
\text { investment cost) }\end{array}$ & 2.5 & 2.4 & 3.5 & 3.5 \\
\hline & $\left(€ / \mathrm{MWh}_{\text {input }}\right)$ & - & - & 3.5 & 3.4 \\
\hline Economic lifespan & (year) & 20 & 20 & 20 & 20 \\
\hline
\end{tabular}

a The biogas efficiency in the Ethanol 1 plant.

$\mathrm{b}$ The number includes not only the biomass input but also 4.57 MW molasses and 1.88 MW enzymes.

${ }^{\mathrm{c}}$ The biomass input.

d The number represent $284 \mathrm{MW}$ biomass and $16 \mathrm{MW}$ electricity used. 